\title{
Initial Vancomycin Dosing Recommendations for Critically III Patients Undergoing Continuous Venovenous Hemodialysis
}

\author{
Lyndsay M van de Vijsel, Sandra A N Walker, Scott E Walker, Sharon Yamashita, Andrew Simor, \\ and Michelle Hladunewich
}

\begin{abstract}
Background: Delaying appropriate antimicrobial therapy for critically ill patients increases the risk of death. Currently, there are insufficient data to guide initial vancomycin dosing for patients undergoing continuous venovenous hemodialysis (CVVHD).

Objective: To develop practical recommendations for initial dosing of vancomycin, based on the pharmacokinetics of this drug in critically ill patients undergoing CVVHD.

Methods: A chart review was conducted for 24 critically ill adult patients who had undergone concurrent CVVHD and vancomycin therapy. Mean pharmacokinetic parameters were determined, along with practical recommendations for initial vancomycin dosing that targeted steady-state trough concentrations for patients receiving intermittent infusions and steady-state levels for those receiving continuous infusions between 15 and $20 \mathrm{mg} / \mathrm{L}$. Monte Carlo simulation was used to develop the initial vancomycin dosing recommendations.

Results: The mean ( $95 \%$ confidence interval) pharmacokinetic parameters for vancomycin (elimination rate constant 0.0315 [0.0254-0.0391], half-life $22.0 \mathrm{~h}$ [17.72-27.24 h], volume of distribution $0.96 \mathrm{~L} / \mathrm{kg}[0.77-1.20 \mathrm{~L} / \mathrm{kg}]$, and clearance $2.4 \mathrm{~L} / \mathrm{h}$ [1.97-2.92 L/h]) indicated that initial intermittent IV dosing of $1.25-1.5 \mathrm{~g}$ q24h or $15 \mathrm{mg} / \mathrm{kg}$ q24h would be suitable. For continuous infusion, a 1.5-g IV loading dose followed by continuous infusion of $1-1.5 \mathrm{~g}$ IV over $24 \mathrm{~h}(42-62 \mathrm{mg} / \mathrm{h})$ would be recommended. However, Monte Carlo simulation revealed that the probability of achieving desired concentrations between 15 and $20 \mathrm{mg} / \mathrm{L}$ with any of these initial regimens is low.
\end{abstract}

Conclusions: There was considerable variation in vancomycin pharmacokinetics in this patient population. The observations reported here raise concerns about the reliability of numerous empiric dosing recommendations derived from small pharmacokinetic studies in heterogeneous populations. Follow-up therapeutic drug monitoring is essential to ensure that concentrations remain within the target range.

Key words: vancomycin, pharmacokinetics, continuous venovenous hemodialysis

\section{RÉSUMÉ}

Contexte : L'instauration tardive d'une antibiothérapie adéquate chez les patients gravement malades accroît le risque de décès. Actuellement, les données sont insuffisantes pour guider la posologie initiale de la vancomycine chez les patients sous hémodialyse veinoveineuse continue (HDVVC).

Objectif : Rédiger des recommandations pratiques relativement à la posologie initiale de la vancomycine, fondées sur la valeur des paramètres pharmacocinétiques de ce médicament chez les patients gravement malades sous HDVVC.

Méthodes : Les dossiers médicaux de 24 patients adultes gravement malades recevant simultanément une HDVVC et un traitement par la vancomycine ont été soumis à une analyse. La valeur moyenne des paramètres pharmacocinétiques a été déterminée et des recommandations pratiques relativement à la posologie initiale de la vancomycine ont été formulées, ciblant des valeurs entre 15 et $20 \mathrm{mg} / \mathrm{L}$ comme concentrations minimales à l'état d'équilibre chez les patients recevant des perfusions intermittentes et comme concentrations à l'état d'équilibre chez les patients recevant des perfusions continues. La méthode de Monte Carlo a été utilisée pour formuler les recommandations relatives à la posologie initiale de la vancomycine.

Résultats : La valeur moyenne (intervalle de confiance à $95 \%$ ) des paramètres pharmacocinétiques de la vancomycine (constante de vitesse d'élimination de 0,0315 [0,0254-0,0391]; demi-vie de 22,0 h [17,72 $27,24 \mathrm{~h}]$; volume de distribution de $0,96 \mathrm{~L} / \mathrm{kg}[0,77-1,20 \mathrm{~L} / \mathrm{kg}]$; et clairance de 2,4 L/h $[1,97-2,92 \mathrm{~L} / \mathrm{h}])$ a étayé la recommandation relative à la posologie initiale de 1,25 à $1,5 \mathrm{~g}$ q24h ou de $15 \mathrm{mg} / \mathrm{kg}$ q $24 \mathrm{~h}$ pour l'administration i.v. intermittente. Quant à la perfusion continue, il serait recommandé d'administrer une dose de charge de $1,5 \mathrm{~g}$ suivie d'une perfusion continue de 1 à $1,5 \mathrm{~g}$ sur $24 \mathrm{~h}$ ( 42 à $62 \mathrm{mg} / \mathrm{h}$ ). La méthode de Monte Carlo a toutefois révélé que la probabilité d'atteindre les concentrations désirées de 15 à $20 \mathrm{mg} / \mathrm{L}$ avec l'un ou l'autre de ces schémas posologiques initiaux est faible.

Conclusions : On a observé des variations considérables de la valeur des paramètres pharmacocinétiques de la vancomycine dans cette population de patients. Ces observations soulèvent des inquiétudes quant à la fiabilité des posologies empiriques recommandées selon de petites études pharmacocinétiques menées dans des populations hétérogènes. Il est essentiel d'effectuer un suivi thérapeutique pharmacologique pour s'assurer que les concentrations demeurent dans la fourchette des valeurs cibles.

Mots clés : vancomycine, pharmacocinétique, hémodialyse veinoveineuse continue

[Traduction par l'éditeur] 


\section{INTRODUCTION}

Oontinuous renal replacement therapy (CRRT) is often prescribed for patients in the intensive care unit (ICU) to manage renal failure, fluid overload, and/or major electrolyte or acid-base abnormalities. ${ }^{1}$ One mode of CRRT that is often used for these patients is continuous venovenous hemodialysis (CVVHD). Patients who undergo CVVHD typically have infections requiring antimicrobial therapy, such as vancomycin. The mortality rate among critically ill patients with severe infections is significantly increased when there is a delay in the administration of appropriate antimicrobial therapy. ${ }^{2-7}$ Data regarding optimal initial vancomycin dosing for ICU patients undergoing CVVHD is currently lacking, and further insight into this therapy may have a positive impact on patient outcomes.

The selection of initial dosing for this patient population is complicated by several factors that have only recently been recognized. For patients with severe infections, the monitoring targets for vancomycin levels have recently changed as a consequence of the poor clinical outcomes that were achieved with previous targets and a better understanding of the pharmacokinetic and pharmacodynamic characteristics of the drug. ${ }^{8-11}$ The new target for vancomycin trough levels is a concentration between 15 and $20 \mathrm{mg} / \mathrm{L}$ for documented or suspected endocarditis, osteomyelitis, and hospital-acquired or ventilatorassociated pneumonia caused by Staphylococcus aureus. ${ }^{9,10,12}$ Trough concentrations above $20 \mathrm{mg} / \mathrm{L}$ should be avoided because of the increased risk of nephrotoxicity associated with higher trough concentrations. ${ }^{13,14}$ Furthermore, recent evidence suggests that the best pharmacokinetic-pharmacodynamic marker for vancomycin may be the ratio of the area under the concentration-time curve over $24 \mathrm{~h}$ to the minimum inhibitory concentration $\left(\mathrm{AUC}_{24 \mathrm{~h}} / \mathrm{MIC}\right)$. Moise-Broder and others ${ }^{15}$ observed that the odds of a successful clinical response among vancomycin-treated patients with an $\mathrm{AUC}_{24 \mathrm{~h}} / \mathrm{MIC}$ value above 350 were about 7 times better than among those with $\mathrm{AUC}_{24 \mathrm{~h}} / \mathrm{MIC}$ less than 350 , and the time to bacterial eradication (microbiological outcome) was significantly shorter among patients with an $\mathrm{AUC}_{24 \mathrm{~h}} / \mathrm{MIC}$ ratio above 400 .

Relevant data regarding vancomycin pharmacokinetics in patients undergoing CVVHD is limited to 2 small evaluations. ${ }^{16,17}$ Joy and others ${ }^{16}$ conducted a pharmacokinetic study in 5 stable patients who were undergoing hemodialysis to evaluate the clearance of vancomycin during a 12-h CVVHD procedure, which was performed in addition to their regularly scheduled hemodialysis. However, because the study patients were stable and had end-stage renal disease, the results of this study cannot be extrapolated to critically ill patients. Davies and others ${ }^{17}$ studied the pharmacokinetics of vancomycin in 4 ICU patients with acute renal failure who were undergoing
CVVHD and concluded that $1 \mathrm{~g}$ every $48 \mathrm{~h}$ would be an appropriate dose for this patient population. Although the study involved an ICU population, the sample size was small, and the desired troughs were targeted to less than $5 \mathrm{mg} / \mathrm{L}$. There is large variability in vancomycin pharmacokinetics among critically ill patients because of rapid and unpredictable changes in cardiac output, serum proteins, and renal and hepatic function. ${ }^{6,718}$ Therefore, a study with sufficient sample size, targeting the currently desired steady-state concentration for vancomycin, is necessary to determine initial dosing recommendations for this population.

The pharmacokinetics of vancomycin in patients managed with intermittent hemodialysis are significantly different from those receiving CRRT because of differences in the filters used and the uninterrupted nature of CRRT. ${ }^{19}$ Therefore, the dosing requirements for patients undergoing CRRT may be very different from those for patients undergoing hemodialysis. Finally, because of the considerable differences among the various types of CRRT systems, dosing information cannot be extrapolated from one mode of CRRT to another. ${ }^{19,20}$

The objective of this study was to develop practical initial dosing recommendations for both intermittent and continuous infusion of vancomycin for critically ill patients undergoing CVVHD. Although a prospective pharmacokinetic study, with sufficient sample size and targeting the currently desired concentrations for vancomycin, would have been the ideal study design, such a study was not feasible because the minimum time to recruit the required number of patients for such a study would have been on the order of 5 years. Therefore, a retrospective study was performed, and Monte Carlo simulation was used to evaluate the robustness of the recommendations.

\section{MATERIALS AND METHODS}

\section{Study Site}

This retrospective study was conducted at Sunnybrook Health Sciences Centre in Toronto, Ontario, a 1275-bed hospital with a total of 84 adult critical care beds. The study was approved by the hospital's Research Ethics Board on January 18, 2008.

\section{Patient Eligibility}

Adult patients (at least 18 years of age) from the medical, surgical, and cardiovascular ICUs were eligible for inclusion if they had been admitted between January 1, 2003, and June 20, 2008, had received at least $24 \mathrm{~h}$ of vancomycin therapy, had concurrently been undergoing CVVHD, and had at least one set of vancomycin concentrations (either assumed steady-state peak and trough concentrations or 2 post-dose concentrations obtained during a period when there was no interruption in 
CVVHD). Patients were excluded if the nursing notes were unclear as to when the vancomycin dose had been administered or when serum sampling for vancomycin determination had been completed. Patients with burns were not eligible because of the significant differences in vancomycin pharmacokinetics in this population..$^{21-28}$

\section{CVVHD Procedure}

CVVHD was administered using Prisma machines (Gambro, Saint-Léonard, Quebec) with the standard accompanying M100 kits, which contain AN69 dialysis membranes. Blood flow rate was set at $100-150 \mathrm{~mL} / \mathrm{min}$. Citrate anticoagulation (acid citrate dextrose solution A, also known as ACD-A) and Normocarb dialysate (Dialysis Solutions Inc, Richmond Hill, Ontario) were employed. Normal saline $(0.9 \% \mathrm{NaCl})$, infused at doses between 0 and $1000 \mathrm{~mL} / \mathrm{h}$, was used as replacement fluid to correct increased levels of serum bicarbonate.

\section{Patient Selection and Study Design}

The pharmacy's computer order entry system was used to generate a list of all patients treated in the ICU for whom vancomycin had been prescribed before June 20, 2008, with the most recent patient appearing first. This information was used to determine which patients had received vancomycin therapy for longer than $24 \mathrm{~h}$. The electronic patient records of laboratory values for these patients were then searched for acceptable vancomycin levels (i.e., either peak and trough concentrations or 2 post-dose concentrations) and for ionized calcium results. At Sunnybrook Health Sciences Centre, the concentration of ionized calcium is determined for all patients undergoing CVVHD (to monitor for hypocalcemia), so these results could be used as an initial screen to identify patients undergoing CVVHD. To confirm patients' eligibility for this study, hospital charts were obtained from Health Data Resources for patients who had taken vancomycin for longer than $24 \mathrm{~h}$ and who had laboratory results for ionized calcium at the time that vancomycin levels were reported. A retrospective chart analysis was completed for patients who met the eligibility criteria.

\section{Data Collection}

Several types of data were extracted from the charts, nursing flow sheets, and electronic records of eligible patients. Background information consisted of age, sex, weight, Acute Physiology and Chronic Health Evaluation (APACHE II) score $^{29}$ upon admission to the ICU, most responsible diagnosis at discharge, immediate cause of death (if applicable), total number of days in the ICU, and overall ICU survival data. If the weight of the patient could not be determined from the chart, a weight of $70 \mathrm{~kg}$ was assumed. Clinical information consisted of the indication for vancomycin therapy, the start and stop dates of the vancomycin therapy, the times on and off vancomycin, the start and stop dates for CVVHD, and the times on and off CVVHD. Microbiological information consisted of the date of sampling for culture, the source of samples obtained for culture, bacteria isolated, antibiotic sensitivity, and date of the first negative result. Vancomycin-related information consisted of dose and schedule, time when the dose was administered, time when the blood sample was drawn, and serum concentration. For the purposes of the current study, a second APACHE II score was calculated as a measure of the patient's severity of illness at the time when samples were drawn for pharmacokinetic analysis of vancomycin. Additional data collected at the time of each sampling for measurement of vancomycin, which were used to identify potential covariates of the pharmacokinetic parameters of vancomycin (volume of distribution and clearance), were serum albumin, blood urea nitrogen (BUN), 24-h urine output, serum creatinine, dialysate rate, ultrafiltration rate, replacement rate, and blood flow rate.

\section{Statistical Analysis}

\section{Pharmacokinetics of Vancomycin}

To completely characterize the pharmacokinetic profile of vancomycin, a 2- or 3-compartment model is necessary. ${ }^{12}$ However, once distribution of the drug is complete, vancomycin follows first-order elimination. ${ }^{30}$ The distribution phase of vancomycin ranges from $30 \mathrm{~min}$ to $1 \mathrm{~h} .{ }^{12}$ As a result, it has become common clinical practice to determine peak vancomycin concentration at least $1 \mathrm{~h}$ after the end of a 1-h infusion, so that first-order pharmacokinetic equations can be used to determine pharmacokinetics in the elimination phase. At Sunnybrook Health Sciences Centre, peak vancomycin concentrations are determined $2 \mathrm{~h}$ after completion of a 1-h infusion to ensure that the distribution phase of vancomycin is complete and the drug is undergoing first-order elimination. The peak vancomycin concentration is obtained for no other reason except that 2 points (steady-state peak and trough or 2 post-dose concentrations) are necessary for use of first-order pharmacokinetic equations to determine the optimal dose and dosing interval to attain target concentrations between 15 and $20 \mathrm{mg} / \mathrm{L}$. The intent of this study was not to completely characterize the pharmacokinetic profile of vancomycin. Rather, the objective was to develop initial dosing recommendations to attain steady-state concentrations (steady-state trough with intermittent dosing or steady-state concentration with continuous infusion) of $15-20 \mathrm{mg} / \mathrm{L}$. All vancomycin concentrations determined at the study institution are based on sampling during first-order elimination; therefore, it was appropriate to use first-order pharmacokinetic equations to achieve the study objective. 
Vancomycin concentrations were analyzed to calculate the following parameters: extrapolated peak and trough concentrations, elimination rate constant $\left(k_{\mathrm{e}}\right)$, half-life $\left(t_{1 / 2}\right)$, volume of distribution $\left(V_{\mathrm{d}}\right)$, volume of distribution per kilogram actual body weight $\left(V_{\mathrm{d}} / \mathrm{kg}\right)$, estimated total body clearance $(\mathrm{Cl})$, the 24-h area under the serum concentration-time curve $\left(\mathrm{AUC}_{24 \mathrm{~h}}\right.$, where $\mathrm{AUC}_{24 \mathrm{~h}}=[$ dose per $24 \mathrm{~h}] / \mathrm{Cl}$ ), desired dose (in milligrams, rounded to nearest $250 \mathrm{mg}$ ), desired weight-based dosing $(\mathrm{mg} / \mathrm{kg})$, and desired dosing interval to generate a trough concentration between 15 and $20 \mathrm{mg} / \mathrm{L}$ (rounded to the nearest convenient dosing interval: every 4, 6, 8, 12, 24, 36, 48, or $72 \mathrm{~h}$ ). To determine the desired dose and interval for intermittent infusion dosing, a desired peak of $30 \mathrm{mg} / \mathrm{L}$ and a desired trough of $18 \mathrm{mg} / \mathrm{L}$ were used. The peak of $30 \mathrm{mg} / \mathrm{L}$ was chosen to minimize fluctuation in levels between peak and trough concentrations. Although peak concentrations are not associated with either efficacy or toxicity, an input value for a peak concentration is required when using first-order pharmacokinetic equations to determine the desired dosing regimen. A trough of $18 \mathrm{mg} / \mathrm{L}$ was chosen as the midpoint of the range of target trough concentrations $(15-20 \mathrm{mg} / \mathrm{L})$. For dosing vancomycin via continuous infusion, the following parameters were calculated: a loading dose (in milligrams, rounded to the nearest $250 \mathrm{mg}$ ), followed by a dose (in terms of both milligrams over $24 \mathrm{~h}$ and milligrams per hour) to generate a steady-state concentration between 15 and $20 \mathrm{mg} / \mathrm{L}$. The following dosing regimens were evaluated: intermittent infusion, weight-based intermittent infusion, continuous infusion, and weight-based continuous infusion. The mean calculated doses and intervals determined for each of these dosing regimens were used as a guide in selecting various regimens for evaluation with Monte Carlo simulation to determine the most desirable dosing recommendations. The most desirable dosing regimens were defined as striking a balance between the highest probability of achieving desirable troughs $(15-20 \mathrm{mg} / \mathrm{L})$, while avoiding intolerably low or high troughs $(<12 \mathrm{mg} / \mathrm{L}$ and $>25 \mathrm{mg} / \mathrm{L}$, respectively). For all Monte Carlo simulations that assessed weight-based dosing, the mean and standard deviation (SD) for patient weight was input as an assumed parameter, which was then used to generate 1 million random selections of weight, $k_{\mathrm{e}}$, and volume of distribution to determine the probability distribution for target levels.

\section{Statistics}

Descriptive data analysis included evaluation of patients' demographic characteristics and microbiological results. Measures of central tendency are reported as means, and measures of variation are reported as SDs for demographic data and $95 \%$ confidence intervals for pharmacokinetic data, along with ranges. The geometric mean and $95 \%$ confidence interval were determined for all pharmacokinetic parameters $\left(k_{e}, t_{1 / 2}\right.$, $V_{\mathrm{d}}$, clearance) because these are known to have a log-normal distribution.

Minimal data are available regarding vancomycin pharmacokinetics in the setting of CVVHD or the existence of covariates that might affect volume of distribution and clearance. Therefore, multiple linear regression (SPSS version 13.0, SPSS Inc, Chicago, Illinois) was used to determine the best model fitting the covariates for prediction of volume of distribution $(\mathrm{L})$ and clearance $(\mathrm{L} / \mathrm{h})$. The parameters entered as independent variables into the regression model were those that would be known before initiation of vancomycin therapy (i.e., not calculated from other parameters input into the regression analysis). The parameters entered as independent variables were age, sex, weight, APACHE II scores at the time of determination of vancomycin levels and ICU admission, albumin, BUN, serum creatinine at the time of determination of vancomycin levels, 24-h urine output, dialysate rate, ultrafiltration rate, blood flow rate, replacement rate, and number of days of CVVHD before determination of vancomycin levels. The linear regression equation based on the best model (i.e., the model with the lowest $p$ value, as determined from the multiple linear regression analysis) might have utility in deriving initial dosing recommendations, provided that the equation was not cumbersome for clinicians. Regardless of its potential utility, the model would identify covariates of the volume of distribution and clearance of vancomycin for patients undergoing CVVHD.

Mean pharmacokinetic data were used as a guide in the selection of dosing regimens to be entered into Monte Carlo simulation (Oracle Crystal Ball, Fusion edition, Oracle Corporation, Redwood Shores, California). Various simulations of interval dosing, weight-based interval dosing $(\mathrm{mg} / \mathrm{kg})$, continuous infusion dosing, and weight-based continuous infusion dosing $(\mathrm{mg} / \mathrm{kg})$ were analyzed using Monte Carlo simulation. The mean and SD for $k_{\mathrm{e}}$, volume of distribution, and weight of the study patients were input, and 1 million iterations were run of possible $k_{\mathrm{e}}$ and $V_{\mathrm{d}}$ values to determine the probability that patients would attain vancomycin steady-state concentrations between 15 and $20 \mathrm{mg} / \mathrm{L}$. For all simulations involving weight-based dosing, the weight was assumed to have a normal distribution, the mean and SD for weight were entered into the simulation, and the weight range permitted for random selection in the simulation was 30 to $200 \mathrm{~kg}$. As part of each Monte Carlo simulation, the probability of attaining an $\mathrm{AUC}_{24 \mathrm{~h}} / \mathrm{MIC}$ ratio of 400 or higher was also assessed. In this part of the analysis, the MIC was assumed to have a normal distribution with a range between 0.5 and $2 \mathrm{mg} / \mathrm{L}$, and the mean was assumed to be $1 \mathrm{mg} / \mathrm{L}$. Based on the coefficient of variation determined for the mean pharmacokinetic values for the 24 patients, the 
Table 1. Demographic and Clinical Characteristics of 24 Patients

\begin{tabular}{|c|c|c|c|c|}
\hline Characteristic & No. (\%) of Patients & Mea & (SD) & Range \\
\hline Age (years) & NA & 64.3 & $(15.0)$ & $36-88$ \\
\hline Sex (no. of males) & $19(79)$ & & & \\
\hline Weight $(\mathrm{kg})^{\star}$ & NA & 81.8 & $(22.9)$ & $51-151$ \\
\hline APACHE II score upon admission to ICU & NA & 24.2 & $(8.8)$ & $12-46$ \\
\hline $\begin{array}{l}\text { Time from admission to determination } \\
\text { of vancomycin level (days) }\end{array}$ & NA & 31.8 & $(32.8)$ & $4-170$ \\
\hline Time in ICU during hospital admission (days) & NA & 54 & $(51)$ & $7-189$ \\
\hline Clinical outcomes & & & & \\
\hline Death & $22(92)$ & & & \\
\hline Death attributable to infection & $13(59)$ & & & \\
\hline Total duration of vancomycin therapy $\dagger$ & NA & 15.2 & $(14.6)$ & $2-52$ \\
\hline Total duration of CVVHD therapy† & NA & 17.3 & (9.8) & $5-40$ \\
\hline
\end{tabular}

95\% confidence interval around the mean pharmacokinetic values $\left(k_{\mathrm{e}}, V_{\mathrm{d}}\right.$, clearance) could be specified within $21 \%$ in this study.

\section{RESULTS}

Twenty-four eligible ICU patients were identified who had been treated with both CVVHD and vancomycin at Sunnybrook Health Sciences Centre between January 1, 2003, and June 20,2008. The chart review was conducted for these 24 patients. The majority of patients were men (19 or 79\%), and the mean age was $64.3 \pm 15.0$ years (range $36-88$ years) (Table 1). Only 2 patients (8\%) did not have a weight recorded in their chart; for these patients, a weight of $70 \mathrm{~kg}$ was assumed. To test the effect of these patients' data on the analysis, their data were removed and the data were re-analyzed to determine vancomycin pharmacokinetics in CVVHD $\left(k_{\mathrm{e}}, V_{\mathrm{d}}\right.$, clearance, and $\left.\mathrm{AUC}_{24 \mathrm{n}}\right)$. The findings were then compared with findings for all 24 patients by means of an unpaired $t$ test. There were no statistically significant differences $(p \geq 0.5)$, and these 2 patients were therefore not excluded from the study.

Almost all of the patients died during the ICU admission (22 or $92 \%$ ), and nearly $60 \%$ of the deaths were infectionrelated (Table 1). Two of the patients who died ( $8 \%$ of the total sample) had samples drawn for determination of vancomycin concentration within $48 \mathrm{~h}$ of their deaths. It is possible that the pharmacokinetics of vancomycin for those patients might have been significantly different from those of the other patients. Therefore, their data were removed and the data were re-analyzed to determine vancomycin pharmacokinetics in CVVHD $\left(k_{\mathrm{e}}\right.$, $V_{\mathrm{d}}$, clearance, and $\left.\mathrm{AUC}_{24 \mathrm{~h}}\right)$. The findings were then compared with findings for all 24 patients by means of an unpaired $t$ test. There were no statistically significant differences $(p \geq 0.9)$, and these 2 patients were therefore not excluded from the study.
For the sake of completeness, the data for all 4 of these patients ( 2 with an estimated weight of $70 \mathrm{~kg}$ and 2 who died within $48 \mathrm{~h}$ after samples were drawn for determination of vancomycin concentrations) were removed, the data were reanalyzed, and the findings were compared with those for the entire sample by means of an unpaired $t$ test. There were no statistically significant differences $(p \geq 0.6)$. Therefore, all patients were retained in the study.

Nearly two-thirds of the patients had documented positive results on microbiological culture (15 or 63\%), most commonly culture of coagulase-negative Staphylococcus from blood (36\% [9 of 25 cultures]) and culture of methicillinsensitive Staphylococcus aureus from blood (12\% [3 of 25 cultures]) or sputum (12\% [3 of 25 cultures]) (Table 2).

The mean pharmacokinetic parameters for vancomycin are detailed in Table 3 . The model that best predicted volume of distribution ( $p=0.001$ and adjusted $\left.R^{2}=0.634\right)$ identified APACHE II score at the time of determination of vancomycin level, APACHE II score at the time of ICU admission, serum creatinine $(\mathrm{s} C r)$ at the time of determination of vancomycin level, 24-h urine output, ultrafiltration rate, blood flow, and patient weight as significant covariates of volume of distribution. The regression equation for this model was $V_{\mathrm{d}}(\mathrm{L})=295$ $+0.548(\mathrm{sCr}$ at time of vancomycin determination $[\mu \mathrm{mol} / \mathrm{L}])+$ 205(ultrafiltration rate $[\mathrm{L} / \mathrm{h}]$ ) -2.490 (APACHE II score at time of vancomycin determination) - 2.383(APACHE II score at time of ICU admission) - 2251(24-h urine output converted to $\mathrm{L} / \mathrm{h}$ ) -12.703 (blood flow $[\mathrm{L} / \mathrm{h}]$ ) -1.01 (weight $[\mathrm{kg}]$ ). The model that best predicted clearance $(p=0.002$ and adjusted $R^{2}=0.521$ ), identified sex, dialysate rate, ultrafiltration rate, blood flow, and patient weight as significant covariates of clearance. The regression equation for this model was clearance $(\mathrm{L} / \mathrm{h})=7.633+1.623($ dialysate rate $[\mathrm{L} / \mathrm{h}])-14.486$ (ultrafiltration rate $[\mathrm{L} / \mathrm{h}])-0.426($ blood flow rate $[\mathrm{L} / \mathrm{h}])$ - 
Table 2. Culture Results

Specimen Source; No. (\%) of Patients or Cultures

\begin{tabular}{|c|c|c|c|c|c|c|}
\hline Variable & Total & Blood & Sputum & Urine & CSF & $\begin{array}{l}\text { Abdominal } \\
\text { Fluid }\end{array}$ \\
\hline $\begin{array}{l}\text { Positive culture result } \\
(n=24 \text { patients) }\end{array}$ & $15 \quad(63)$ & $13(54)$ & $3(13)$ & $2(8)$ & $1(4)$ & $1(4)$ \\
\hline $\begin{array}{l}\text { Microbiological culture result } \\
(n=25 \text { cultures })^{*}\end{array}$ & $25(100)$ & $18(72)$ & $3(12)$ & $2(8)$ & $1(4)$ & $1(4)$ \\
\hline $\begin{array}{l}\text { Coagulase-negative Staphylococcust } \\
\text { Methicillin-sensitive }\end{array}$ & $10 \quad(40)$ & $9(36)$ & 0 & 0 & $1(4)$ & 0 \\
\hline Staphylococcus aureus & $(28)$ & $3(12)$ & $3(12)$ & $1(4)$ & 0 & 0 \\
\hline $\begin{array}{l}\text { Methicillin-resistant } \\
\text { Staphylococcus aureus }\end{array}$ & 0 & 0 & 0 & 0 & 0 & 0 \\
\hline Enterococcus unspeciated & (8) & 0 & 0 & $1(4)$ & 0 & $1(4)$ \\
\hline Enterococcus faecalis & (12) & $3(12)$ & 0 & 0 & 0 & 0 \\
\hline Enterococcus faecium & 0 & 0 & 0 & 0 & 0 & 0 \\
\hline Streptococcus mitus & (4) & (4) & 0 & 0 & 0 & 0 \\
\hline Streptococcus anginosus-milleri & (4) & (4) & 0 & 0 & 0 & 0 \\
\hline Streptococcus oralis & (4) & (4) & 0 & 0 & 0 & 0 \\
\hline
\end{tabular}

CSF = cerebrospinal fluid.

*The percentages refer to the proportion of cultures, rather than the proportion of patients with that organism.

tThree of the positive results for coagulase-negative Staphylococcus probably represented contamination.

\section{Table 3. Pharmacokinetic Parameters for Vancomycin from Earliest Steady-State Peak and Trough Concentrations $(n=24)$}

\begin{tabular}{|c|c|c|c|}
\hline Parameter & Mean* & 95\% Confidence Interval & Range \\
\hline$\overline{k_{\mathrm{e}}}\left(\mathrm{h}^{-1}\right)$ & 0.0315 & $0.0254-0.0391$ & $0.0109-0.0980$ \\
\hline$t_{1 / 2}(h)$ & 22.0 & $17.72-27.24$ & $7.1-63.7$ \\
\hline$V_{d}(L)$ & 76.1 & 63.9-90.6 & $27.8-218.5$ \\
\hline$V_{\mathrm{d}}(\mathrm{L} / \mathrm{kg})$ & 0.96 & $0.77-1.20$ & $0.18-3.12$ \\
\hline $\mathrm{Cl}(\mathrm{L} / \mathrm{h})$ & 2.4 & $1.97-2.92$ & $1.3-7.5$ \\
\hline $\mathrm{AUC}_{24 \mathrm{~h}}\left(\mathrm{mg} \mathrm{g}^{\star} \mathrm{h} / \mathrm{L}\right)$ & 403 & $334-486$ & 89-792 \\
\hline
\end{tabular}

0.028(weight $[\mathrm{kg}])-1.885$ (if male). Although the regression equations were statistically significant, each explained less than $65 \%$ of the variability in volume of distribution or clearance, respectively. Furthermore, the use of these equations to calculate initial dosing recommendations would necessitate determining several parameters for input into cumbersome equations for volume of distribution and clearance. This would be impractical, requiring excessive effort with a limited chance of improving initial dosing of vancomycin.

The half-life of vancomycin for critically ill patients undergoing CVVHD was on the order of $22 \mathrm{~h}$. Therefore, a dosing interval for intermittent infusion of every $24 \mathrm{~h}$ (i.e., about every one half-life) would be rational and convenient. Based on the determined mean $k_{\mathrm{e}}$ and volume of distribution and the variability around each of these values, Monte Carlo simulation of 1 million iterations indicated that intermittent dosing of $1.25-1.5 \mathrm{~g}$ IV q24h would provide the highest probability of attaining a target trough between 15 and $20 \mathrm{mg} / \mathrm{L}$. This regimen would also minimize the probability of intolerably low troughs $(<12 \mathrm{mg} / \mathrm{L})$ and high troughs $(>25 \mathrm{mg} / \mathrm{L})$, while achieving an $\mathrm{AUC}_{24 \mathrm{~h}} / \mathrm{MIC}$ ratio of 400 or more in at least $63 \%$ of patients receiving $1.25 \mathrm{~g}$ IV q24h and $71 \%$ of patients

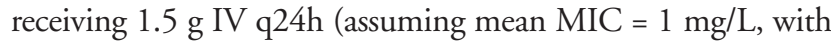
a range from 0.5 to $2 \mathrm{mg} / \mathrm{L}$ as a normal distribution) (Table 4). Alternatively, intermittent dosing of $15 \mathrm{mg} / \mathrm{kg}$ (rounded to the nearest $250 \mathrm{mg}$ ) IV q24h may be used to provide a similar probability of attaining target trough concentrations and an $\mathrm{AUC}_{24 \mathrm{~h}} / \mathrm{MIC}$ ratio of 400 or more in at least $71 \%$ of patients, while minimizing excessively high or low trough concentrations (Table 4). If administering vancomycin by continuous infusion is desired, then a 1.5-g IV loading dose followed by $1-1.5 \mathrm{~g}$ infused over $24 \mathrm{~h}(42-62 \mathrm{mg} / \mathrm{h})$ or a $20 \mathrm{mg} / \mathrm{kg}$ loading dose followed by $15 \mathrm{mg} / \mathrm{kg}$ infused over $24 \mathrm{~h}$ would provide a similar probability of attaining steady-state vancomycin concentrations between 15 and $20 \mathrm{mg} / \mathrm{L}$ and an $\mathrm{AUC}_{24 \mathrm{~h}} / \mathrm{MIC}$ ratio of 400 or more (Table 5).

Importantly, Monte Carlo simulation revealed that because of the considerable variability of vancomycin 
Table 4. Monte Carlo Simulation of Dosing Recommendations for Intermittent IV Infusions of Vancomycin

Predicted Certainty (\%)

\begin{tabular}{|c|c|c|c|c|}
\hline Regimen & Trough $15-20 \mathrm{mg} / \mathrm{L}$ & Trough $<12 \mathrm{mg} / \mathrm{L}$ & Trough > $25 \mathrm{mg} / \mathrm{L}$ & $\mathrm{AUC}_{24 \mathrm{~h}} / \mathrm{MIC} \geq 400^{*}$ \\
\hline $1 \mathrm{~g} \mathrm{q} 24 \mathrm{~h}$ & 12 & 51 & 19 & 52 \\
\hline $1.25 \mathrm{~g} \mathrm{q} 24 \mathrm{~h}$ & 13 & 41 & 27 & 63 \\
\hline $1.5 \mathrm{~g} \mathrm{q} 24 \mathrm{~h}$ & 13 & 34 & 35 & 71 \\
\hline $1.75 \mathrm{~g} \mathrm{q} 24 \mathrm{~h}$ & 12 & 28 & 42 & 78 \\
\hline $2.0 \mathrm{~g} \mathrm{q} 24 \mathrm{~h}$ & 11 & 24 & 48 & 83 \\
\hline $15 \mathrm{mg} / \mathrm{kg} \mathrm{q} 24 \mathrm{~h}$ & 12 & 43 & 26 & 71 \\
\hline $10 \mathrm{mg} / \mathrm{kg} \mathrm{q} 24 \mathrm{~h}$ & 10 & 60 & 14 & 41 \\
\hline
\end{tabular}

$\mathrm{AUC}_{24 \mathrm{~h}}=$ area under the concentration-time curve over $24 \mathrm{~h}, \mathrm{MIC}=$ minimum inhibitory concentration.

* MIC was assumed to have a normal distribution, with a range between 0.5 and $2 \mathrm{mg} / \mathrm{L}$ and a mean value of $1 \mathrm{mg} / \mathrm{L}$,

with 1 million iterations using Monte Carlo simulation.

Table 5. Monte Carlo Simulation of Dosing Recommendations for Continuous IV Infusions of Vancomycin

\begin{tabular}{|c|c|c|c|c|}
\hline \multirow[b]{2}{*}{ Regimen } & \multicolumn{4}{|c|}{ Predicted Certainty (\%) } \\
\hline & $\mathrm{C}^{*} 15-20 \mathrm{mg} / \mathrm{L}$ & $\mathrm{C}^{*}<12 \mathrm{mg} / \mathrm{L}$ & $\mathrm{C}^{*}>25 \mathrm{mg} / \mathrm{L}$ & $\mathrm{AUC}_{24 \mathrm{~h}} / \mathrm{MIC} \geq 400 \dagger$ \\
\hline 1.5-g loading dose & 24 & 13 & 30 & NA \\
\hline 2-g loading dose & 16 & 4 & 55 & NA \\
\hline $\begin{array}{l}1 \mathrm{~g} / 24 \mathrm{~h} \text { continuous infusion } \\
(42 \mathrm{mg} / \mathrm{h})\end{array}$ & 16 & 29 & 31 & 52 \\
\hline $\begin{array}{l}1.25 \mathrm{~g} / 24 \mathrm{~h} \text { continuous infusion } \\
(52 \mathrm{mg} / \mathrm{h})\end{array}$ & 15 & 20 & 43 & 63 \\
\hline $\begin{array}{l}1.5 \mathrm{~g} / 24 \mathrm{~h} \text { continuous infusion } \\
(62.5 \mathrm{mg} / \mathrm{h})\end{array}$ & 13 & 13 & 53 & 71 \\
\hline 20 mg/kg loading dose & 21 & 14 & 36 & NA \\
\hline $\begin{array}{l}15 \mathrm{mg} / \mathrm{kg} \text { per } 24 \mathrm{~h} \text { continuous } \\
\text { infusion }\end{array}$ & 15 & 23 & 40 & 59 \\
\hline $25 \mathrm{mg} / \mathrm{kg}$ loading dose & 16 & 7 & 52 & NA \\
\hline $\begin{array}{l}20 \mathrm{mg} / \mathrm{kg} \text { per } 24 \mathrm{~h} \text { continuous } \\
\text { infusion }\end{array}$ & 13 & 13 & 55 & 72 \\
\hline
\end{tabular}

pharmacokinetics in critically ill patients undergoing CVVHD, even the best initial dosing recommendations based on mean pharmacokinetic data did not have a high probability of attaining the desired concentration range of vancomycin. This highlights the importance of therapeutic drug monitoring in this patient population.

\section{DISCUSSION}

To date, there have been insufficient data regarding the pharmacokinetics of vancomycin in critically ill patients undergoing CVVHD to guide initial dosing. The objective of this study was to develop practical recommendations for initial vancomycin dosing based on the pharmacokinetics of the drug in this patient population, targeting steady-state concentrations between 15 and $20 \mathrm{mg} / \mathrm{L}$.

The reported overall ICU mortality rate ranges from 30\% to $60 \% .^{31,32}$ The mortality rate for critically ill patients undergoing dialysis ranges from $30 \%$ to $83 \% .^{33-36}$ The high mortality rate observed in the current study, 92\%, may have been due in part to the use of data for only the sickest subset of critically ill patients, that is, trauma patients with life-threatening injuries and serious infections requiring vancomycin therapy and patients with acute renal failure requiring CVVHD. The mortality due to infection in this investigation was about $60 \%$, in keeping with the morality rates reported for critically ill patients with infections such as bacteremia and pneumonia. ${ }^{37-41}$

The results of this investigation indicate that vancomycin has an extended elimination half-life $(22.0 \mathrm{~h})$, an expanded volume of distribution $(0.96 \mathrm{~L} / \mathrm{kg})$, and a clearance of $2.4 \mathrm{~L} / \mathrm{h}$ in critically ill patients undergoing CVVHD. Previous studies have demonstrated that there are significant changes in both clearance and volume of distribution throughout the course of vancomycin therapy in ICU patients. ${ }^{42-44}$ del Mar Fernández and others ${ }^{44}$ observed that the mean volume of distribution of vancomycin among 46 critically ill patients was $1.69 \mathrm{~L} / \mathrm{kg}$, nearly double that observed in healthy adult subjects with normal renal function $(0.4-1 \mathrm{~L} / \mathrm{kg}) \cdot{ }^{30,45-47}$ In a population-based 
pharmacokinetic study by Llopis-Salvia and others, ${ }^{43}$ the volume of distribution of the central and peripheral compartments was $0.41 \mathrm{~L} / \mathrm{kg}$ and $1.32 \mathrm{~L} / \mathrm{kg}$, respectively.

The volume of distribution of medications may be increased in critically ill patients for a number of reasons, including sepsis-induced third spacing. Inflammatory mediators that are released during sepsis affect the vascular endothelium, causing increased capillary permeability and ultimately leading to an expanded volume of extracellular fluids. ${ }^{48,49} \mathrm{~A}$ study by Pea and others ${ }^{50}$ revealed that the use of vasoactive drugs such as dobutamine and dopamine may alter vancomycin pharmacokinetics, resulting in possibly subtherapeutic concentrations. It was hypothesized that this may be due to improvements in cardiac output and/or renal blood flow. In addition to considerable intrasubject variability, the wide range of pharmacokinetic results indicates substantial intersubject variability in the study population.

When the pharmacokinetics of vancomycin in critically ill patients undergoing CVVHD are compared to the pharmacokinetics associated with other modes of CRRT, there are notable differences. DelDot and others ${ }^{19}$ and Santré and others ${ }^{51}$ both investigated vancomycin pharmacokinetics in patients undergoing continuous venovenous hemodiafiltration. DelDot and others ${ }^{19}$ found that vancomycin had a half-life of $15.6 \mathrm{~h}$ and a clearance of $2.5 \mathrm{~L} / \mathrm{h}$ in this setting. Similarly, Santré and others ${ }^{11}$ found that vancomycin had a half-life of $13.6 \mathrm{~h}$ and a clearance of $2.3 \mathrm{~L} / \mathrm{h}$. The results of the current study indicate that the clearance of vancomycin in critically ill patients undergoing CVVHD is comparable to that of patients undergoing continuous venovenous hemodiafiltration. As such, the longer half-life of vancomycin in CVVHD may be due to a larger volume of distribution.

The options for initial vancomycin dosing based on mean pharmacokinetic data from this study and Monte Carlo simulation are summarized in Tables 4 and 5. These results differ from the dosing suggestions of both Joy and others ${ }^{16}$ and Davies and others. ${ }^{17}$ Joy and others ${ }^{16}$ prospectively investigated 8 patients with end-stage renal disease. The dosing recommendations developed in that pharmacokinetic study to maintain plasma concentrations of $20 \mathrm{mg} / \mathrm{L}$ ranged from 800 to 1750 mg every $24 \mathrm{~h}$, according to the type of dialysis filter, ultrafiltration and dialysate rates, and the patient's residual renal function. The dosing suggestions of Joy and others ${ }^{16}$ were based on the results for patients with stable renal disease. Therefore, it cannot be assumed that the outcomes from that study would be applicable to ICU patients undergoing CVVHD, because of the wide variability in the pharmacokinetics of vancomycin in these patients and the differences in types of dialysis. ${ }^{43,44}$ However, the results of the current study for initial intermittent dosing of $1.25-1.5 \mathrm{~g}$ IV q24h in critically ill patients undergoing CVVHD fall within the range recommended by Joy and others. ${ }^{16}$ In the investigation by Davies and others, ${ }^{17} 4 \mathrm{ICU}$ patients were managed with concurrent vancomycin and CVVHD. A vancomycin dose of $1 \mathrm{~g} \mathrm{q} 48 \mathrm{~h}$ was suggested, with a goal of vancomycin troughs less than $5 \mathrm{mg} / \mathrm{L}$. In contrast, the current study aimed for steady-state concentrations between 15 and $20 \mathrm{mg} / \mathrm{L}$. It is therefore reasonable for the nomogram developed here to suggest higher doses and more frequent administration of vancomycin to attain the updated target trough concentration.

There are no data examining continuous infusion of vancomycin in this subset of patients. This dosing strategy has been explored in other patient populations and may enable more rapid attainment and greater control of target concentrations. ${ }^{52-58}$ It may also have a lower risk of adverse reactions, including renal damage, allergic reactions, and phlebitis, ${ }^{55}$ and may be associated with reduced cost. ${ }^{52-54}$ As a result of the growing interest in the use of continuous infusions of vancomycin in clinical practice, the mean pharmacokinetic data derived from this study were used to determine initial dosing recommendations for practitioners interested in this mode of administration.

del Mar Fernández and others ${ }^{44}$ conducted a pharmacokinetic-pharmacodynamic analysis of vancomycin in patients in the medical ICU but excluded patients requiring renal replacement therapy. Those investigators conducted a Monte Carlo simulation to identify the probability of attaining an $\mathrm{AUC}_{24 \mathrm{~h}} / \mathrm{MIC}$ ratio above 400 with various daily dosing regimens. For a dosing regimen of $1250 \mathrm{mg}$ IV q24h, they observed a $50 \%$ probability of attaining an $\mathrm{AUC}_{24 \mathrm{~h}} / \mathrm{MIC}$ target above 400 for patients with vancomycin-susceptible strains of $S$. aureus. The dosing recommendations suggested in the current study provide a probability of at least $50 \%$ of attaining an $\mathrm{AUC}_{24 \mathrm{~h}} / \mathrm{MIC}$ ratio of 400 or greater and are therefore comparable to the results of del Mar Fernández and others. ${ }^{44}$ However to achieve these targets, higher-than-desired trough concentrations may occur more frequently (Tables 4 and 5).

Although the current study of vancomycin therapy for 24 ICU patients undergoing CVVHD is the largest study to date in this patient population, the Monte Carlo simulation demonstrated that the predictive ability of the derived nomogram (which used mean pharmacokinetic parameters to achieve target concentrations) was low, with a probability of about $12 \%$ to $16 \%$. However, these recommendations may be useful for initial dosing, provided that appropriate follow-up therapeutic drug monitoring is performed. It was our hope to strengthen the predictive ability of the empiric dosing nomogram by incorporating covariates that significantly affect vancomycin pharmacokinetics. Although statistically significant linear regression models were obtained for both volume of distribution and clearance, with covariates for both of these parameters, the regression equations for volume of 
distribution and clearance were too cumbersome and had little expected benefit for improving initial vancomycin dosing. However, the analysis was important in identifying APACHE II score at the time of determination of vancomycin levels, APACHE II score at the time of ICU admission, serum creatinine at the time of determination of vancomycin levels, 24-h urine output, ultrafiltration rate, blood flow, and patient weight as significant covariates of volume of distribution, and sex, dialysate rate, ultrafiltration rate, blood flow rate, and weight as statistically significant covariates of clearance in critically ill patients undergoing CVVHD.

The Monte Carlo simulation highlighted that the exclusive use of mean pharmacokinetic data as a basis for the development of dosing recommendations in a heterogeneous population with considerable intra- and inter-subject variability will not reliably attain target concentrations in every patient, a belief that many clinicians have when they select published dosing recommendations to treat their patients. The few previously published studies examining vancomycin dosing in critically ill patients undergoing CRRT have made recommendations based solely on mean pharmacokinetic data obtained from small numbers of patients. ${ }^{17,19,59}$ Our observations from the Monte Carlo simulation raise questions about the reliability of dosing recommendations based solely on small pharmacokinetic studies for medications used in critically ill patients undergoing CRRT and highlight the importance of continued monitoring of vancomycin concentrations to individualize therapy after initial dosing.

Several weaknesses are inherent to a retrospective study design, including unrecognized confounding factors that may bias the results. In addition, further limitations specific to this study design and potentially introducing error or bias may include assumptions of apparent steady-state vancomycin peak and trough concentrations; assumptions about the timing of vancomycin dosing and the timing of serum sampling for determination of drug concentration; determination of total body clearance of vancomycin by calculation, rather than by direct measurement of blood and dialysate outlet samples; determination of area under the curve by calculation rather than by generating a complete serum concentration versus time profile for vancomycin in each patient; and the inability to control for potential variables relating to CVVHD (filters used or dialysate flow rate) or patient-specific factors (third-space volume).

\section{CONCLUSIONS}

This study has generated recommendations for initial vancomycin dosing by either intermittent or continuous infusion in critically ill patients who are undergoing CVVHD and has evaluated the robustness of these recommendations using Monte Carlo simulation. The study has demonstrated that the pharmacokinetics of vancomycin in this patient population are highly variable. Thus, reliable attainment of desired steady-state concentrations with a standard initial dose is not feasible for the majority of these patients. Therefore, therapeutic drug monitoring is essential to refine initial dosing to achieve target concentrations between 15 and $20 \mathrm{mg} / \mathrm{L}$. Our observations raise concerns about the robustness of numerous drug dosing recommendations that have been derived from small pharmacokinetic studies in heterogeneous populations.

\section{References}

1. Kutsogiannis D. Continuous venovenous hemodiafiltration for renal failure and sepsis. CMAJ 2000;162(4):537-538.

2. Garnacho-Montero J, Ortiz-Leyba C, Herrera-Melero I, Aldabó-Pallás T, Cayuela-Dominguez A, Marquez-Vacaro JA, et al. Mortality and morbidity attributable to inadequate empirical antimicrobial therapy in patients admitted to the ICU with sepsis: a matched cohort study. J Antimicrob Chemother 2008;61(2):436-441.

3. Luna CM, Vujacich P, Niederman MS, Vay C, Gherardi C, Matera J, et al. Impact of BAL data on the therapy and outcome of ventilatorassociated pneumonia. Chest 1997;111(3):676-685.

4. Ibrahim EH, Sherman G, Ward S, Fraser VJ, Kollef MH. The influence of inadequate antimicrobial treatment of bloodstream infections on patient outcomes in the ICU setting. Chest 2000;118(1):146-155.

5. Leibovici L, Shraga I, Drucker M, Konigsberger H, Samra Z, Pitlik SD. The benefit of appropriate empirical antibiotic treatment in patients with bloodstream infection. J Intern Med 1998;244(5):379-386.

6. Lodise TP, McKinnon PS, Swiderski L, Rybak MJ. Outcomes analysis of delayed antibiotic treatment for hospital-acquired Staphylococcus aureus bacteremia. Clin Infect Dis 2003;36(11):1418-1423.

7. Kollef MH, Sherman G, Ward S, Fraser VJ. Inadequate antimicrobial treatment of infections: a risk factor for hospital mortality among critically ill patients. Chest 1999;115(2):462-474.

8. Baddour LM, Wilson WR, Bayer AS, Fowler VG Jr, Bolger AF, Levison $\mathrm{ME}$, et al. Infective endocarditis: diagnosis, antimicrobial therapy, and management of complications: a statement for healthcare professionals from the Committee on Rheumatic Fever, Endocarditis, and Kawasaki Disease, Council on Cardiovascular Disease in the Young, and the Councils on Clinical Cardiology, Stroke, and Cardiovascular Surgery and Anesthesia, American Heart Association: endorsed by the Infectious Diseases Society of America. Circulation 2005;111(23):e394-e434.

9. Tunkel AR, Hartman BJ, Kaplan SL, Kaufman BA, Roos KL, Scheld WM, et al. Practice guidelines for the management of bacterial meningitis. Clin Infect Dis 2004;39(9):1267-1284.

10. American Thoracic Society; Infectious Diseases Society of America. Guidelines for the management of adults with hospital-acquired, ventilatorassociated, and healthcare-associated pneumonia. Am J Respir Crit Care Med 2005;171(4):388-416.

11. Hidayat L, Hsu D, Quist R, Shriner K, Wong-Beringer A. High-dose vancomycin therapy for methicillin-resistant Staphylococcus aureus infections. Arch Intern Med 2006;166(19):2138-2144.

12. Rybak M, Lomaestro B, Rotschafer JC, Moellering R Jr, Craig W, Billeter $\mathrm{M}$, et al. Therapeutic monitoring of vancomycin in adult patients: a consensus review of the American Society of Health-System Pharmacists, the Infectious Diseases Society of America, and the Society of Infectious Diseases Pharmacists. Am J Health Syst Pharm 2009;66(1):82-98.

13. Lodise TP, Patel N, Lomaestro BM, Rodvold KA, Drusano GL. Relationship between initial vancomycin concentration-time profile and nephrotoxicity among hospitalized patients. Clin Infect Dis 2009;49(4):507-514.

14. Lodise TP, Lomaestro B, Graves J, Drusano GL. Larger vancomycin doses (at least four grams per day) are associated with an increased incidence of nephrotoxicity. Antimicrob Agents Chemother 2008;52(4):1330-1336. 
15. Moise-Broder P, Forrest A, Birmingham M. Pharmacodynamics of vancomycin and other antimicrobials in patients with Staphylococcus aureus lower respiratory tract infections. Clin Pharmacokinet 2004; 43(13):925-942.

16. Joy M, Matzke G, Frye R, Palevsky P. Determinants of vancomycin clearance by continuous venovenous hemofiltration and continuous venovenous hemodialysis. Am J Kidney Dis 1998;31(6):1019-1027.

17. Davies SP, Azadian BS, Kox WJ, Brown EA. Pharmacokinetics of ciprofloxacin and vancomycin in patients with acute renal failure treated by continuous haemodialysis. Nephrol Dial Transplant 1992;7(8):848-854.

18. Pea F, Viale P, Furlanut M. Antimicrobial therapy in critically ill patients: a review of pathophysiological conditions responsible for altered disposition and pharmacokinetic variability. Clin Pharmacokinet 2005; 44(10):1009-1034.

19. DelDot ME, Lipman J, Tett SE. Vancomycin pharmacokinetics in critically ill patients receiving continuous venovenous haemodiafiltration. Br J Clin Pharmacol 2004;58(3):259-268.

20. Reetze-Bonorden P, Böhler J, Keller E. Drug dosage in patients during continuous renal replacement therapy. Pharmacokinetic and therapeutic considerations. Clin Pharmacokinet 1993;24(5):362-379.

21. Boucher B, Kuhl D, Hickerson W. Pharmacokinetics of systemically administered antibiotics in patients with thermal injury. Clin Infect Dis 1992;14(2):458-463.

22. Weinbren MJ. Pharmacokinetics of antibiotics in burn patients. J Antimicrob Chemother 1999;44(3):319-327.

23. Brater DC, Bawdon RE, Anderson SA, Purdue GF, Hunt JL. Vancomycin elimination in patients with burn injury. Clin Pharmacol Ther 1986;39(6):631-634.

24. Rybak M, Albrecht L, Berman J, Warbasse L, Svensson C. Vancomycin pharmacokinetics in burn patients and intravenous drug abusers. Antimicrob Agents Chemother 1990;34(5):792-795.

25. Dell'Aquila AM, McCulloch JA, Mamizuka EM, Santos SR, Pereira CA. Serum levels of vancomycin should be monitored in burn patients. Burns 2004;30(4):386-7.

26. Garrelts JC, Peterie JD. Altered vancomycin dose vs. serum concentration relationship in burn patients. Clin Pharmacol Ther 1988;44(1):9-13.

27. Dailly E, Le Floch R, Deslandes G, Pannier M, Jolliet R. Influence of glomerular filtration rate on the clearance of vancomycin administered by continuous infusion in burn patients. Int $J$ Antimicrob Agents 2008;31(6):537-539.

28. Zokufa H, Solem L, Rodvold K, Crossley K, Fischer J, Rotschafer J. The influence of serum albumin and alpha 1-acid glycoprotein on vancomycin protein binding in patients with burn injuries. J Burn Care Rehabil 1989;10(5):425-428.

29. Knaus W, Draper E, Wagner D, Zimmerman J. APACHE II: a severity of disease classification system. Crit Care Med 1985;13(10):818-829.

30. Rybak MJ. The pharmacokinetic and pharmacodynamic properties of vancomycin. Clin Infect Dis 2006; 42 Suppl 1:S35-S39.

31. Rocker G, Cook D, Sjokvist P, Weaver B, Finfer S, McDonald E, et al. Clinician predictions of intensive care unit mortality. Crit Care Med 2004;32(5):1149-1154.

32. Ratheiser K, Schiefermeier M, Kranz A, Kramer L, Madl C, Schenk P, et al. Sudden increase in ICU-mortality rate: a look behind the stage applying continuous quality improvement [abstract]. Crit Care 1997;1(Suppl 1):P130.

33. Ghahramani N, Shadrou S, Hollenbeak C. A systematic review of continuous renal replacement therapy and intermittent haemodialysis in management of patients with acute renal failure. Nephrology 2008;13(7):570-578.

34. Tolwani AJ, Campbell RC, Stofan BS, Lai KR, Oster RA, Wille KM. Standard versus high-dose CVVHDF for ICU-related acute renal failure. J Am Soc Nephrol 2008;19(6):1233-1238.

35. Waikar S, Curhan G, Wald R, McCarthy E, Chertow G. Declining mortality in patients with acute renal failure, 1988 to 2002. J Am Soc Nephrol 2006;17(4):1143-1150.
36. Brar H, Olivier J, Lebrun C, Gabbard W, Fulop T, Schmidt D. Predictors of mortality in a cohort of intensive care unit patients with acute renal failure receiving continuous renal replacement therapy. Am J Med Sci 2008;335(5):342-347.

37. Ibrahim EH, Ward S, Sherman G, Kollef MH. A comparative analysis of patients with early-onset vs late-onset nosocomial pneumonia in the ICU setting. Chest 2000;117(5):1434-42.

38. Smith RL, Meixler SM, Simberkoff MS. Excess mortality in critically ill patients with nosocomial bloodstream infections. Chest 1991;100(1): $164-167$

39. Bercault N, Boulain T. Mortality rate attributable to ventilator-associated nosocomial pneumonia in an adult intensive care unit: a prospective case-control study. Crit Care Med 2001;29(12):2303-2309.

40. Blot SI, Vandewoude KH, Hoste EA, Colardyn FA. Outcome and attributable mortality in critically ill patients with bacteremia involving methicillin-susceptible and methicillin-resistant Staphylococcus aureus. Arch Intern Med 2002;162(19):2229-2235.

41. Vallés J, Pobo A, García-Esquirol O, Mariscal D, Real J, Fernández R. Excess ICU mortality attributable to ventilator-associated pneumonia: the role of early vs late onset. Intensive Care Med 2007;33(8):1363-1368.

42. Polard E, Le Bouquin V, Le Corre P, Kerebel C, Trout H, Feuillu A, et al. Non steady state and steady state PKS Bayesian forecasting and vancomycin pharmacokinetics in ICU adult patients. Ther Drug Monit 1999;21(4):395-403

43. Llopis-Salvia P, Jiménez-Torres N. Population pharmacokinetic parameters of vancomycin in critically ill patients. J Clin Pharm Ther 2006;31(5): 447-454.

44. del Mar Fernández de Gatta Garcia M, Revilla N, Calvo MV, DominguezGil A, Sánchez Navarro A. Pharmacokinetic/pharmacodynamic analysis of vancomycin in ICU patients. Intensive Care Med 2007;33(2):279-285.

45. Golper TA, Noonan HM, Elzinga L, Gilbert D, Brummett R, Anderson $\mathrm{JL}$, et al. Vancomycin pharmacokinetics, renal handling, and nonrenal clearances in normal human subjects. Clin Pharmacol Ther 1988;43(5): 565-570.

46. Blouin R, Bauer L, Miller D, Record K, Griffin W. Vancomycin pharmacokinetics in normal and morbidly obese subjects. Antimicrob Agents Chemother 1982;21(4):575-580.

47. Matzke GR, Zhanel GG, Guay DR. Clinical pharmacokinetics of vancomycin. Clin Pharmacokinet 1986;11(4):257-282.

48. Depaepe P, Belpaire F, Buylaert W. Pharmacokinetic and pharmacodynamic considerations when treating patients with sepsis and septic shock. Clin Pharmacokinet 2002;41(14):1135-1151.

49. Roberts J, Lipman J. Antibacterial dosing in intensive care: pharmacokinetics, degree of disease and pharmacodynamics of sepsis. Clin Pharmacokinet 2006;45(8):755-773.

50. Pea F, Porreca L, Baraldo M, Furlanut M. High vancomycin dosage regimens required by intensive care unit patients cotreated with drugs to improve haemodynamics following cardiac surgical procedures. $J$ Antimicrob Chemother 2000;45(3):329-335.

51. Santré C, Leroy O, Simon M, Georges H, Guery B, Beuscart C, et al. Pharmacokinetics of vancomycin during continuous hemodiafiltration. Intensive Care Med 1993;19(6):347-350.

52. Wysocki M, Delatour F, Faurisson F, Rauss A, Pean Y, Misset B, et al. Continuous versus intermittent infusion of vancomycin in severe staphylococcal infections: prospective multicenter randomized study. Antimicrob Agents Chemother 2001;45(9):2460-2467.

53. Kitzis M, Goldstein F. Monitoring of vancomycin serum levels for the treatment of staphylococcal infections. Clin Microbiol Infect 2006; 12(1):92-95.

54. Grof T, Barrett M, Schmelzer T, Christmas A, Norton H, Sing R. A retrospective comparison of vancomycin continuous infusion and intermittent dosing in surgery patients with pneumonia. Chest 2007; 132(4):497S 
55. Vuagnat A, Stern R, Lotthe A, Schuhmacher H, Duong M, Hoffmeyer P, et al. High dose vancomycin for osteomyelitis: continuous vs. intermittent infusion. J Clin Pharm Ther 2004;29(4):351-357.

56. James J, Palmer S, Levine D, Rybak M. Comparison of conventional dosing versus continuous-infusion vancomycin therapy for patients with suspected or documented gram-positive infections. Antimicrob Agents Chemother 1996;40(3):696-700.

57. Pea F, Furlanut M, Negri C, Pavan F, Crapis M, Cristini F, et al. Prospectively validated dosing nomograms for maximizing the pharmacodynamics of vancomycin administered by continuous infusion in critically ill patients. Antimicrob Agents Chemother 2009;53(5):1863-1867.

58. Thomson AH, Staatz CE, Tobin CM, Gall M, Lovering AM. Development and evaluation of vancomycin dosage guidelines designed to achieve new target concentrations. J Antimicrob Chemother 2009;63(5):1050-1057.

59. Boereboom FT, Ververs FF, Blankestijn PJ, Savelkoul TJ, van Dijk A. Vancomycin clearance during continuous venovenous haemofiltration in critically ill patients. Intensive Care Med 1999;25(10):1100-1104.

Lyndsay $\mathbf{M}$ van de Vijsel, BScPhm, is with the Department of Pharmacy, St Boniface Hospital, Winnipeg, Manitoba.
Sandra A N Walker, BSC, BSCPhm, ACPR, PharmD, FCSHP, is with the Department of Pharmacy, Sunnybrook Health Sciences Centre, Toronto, Ontario.

Scott E Walker, , MScPhm, FCSHP, is with the Department of Pharmacy, Sunnybrook Health Sciences Centre, Toronto, Ontario.

Sharon Yamashita, BScPhm, PharmD, FCSHP, is with the Department of Pharmacy, Sunnybrook Health Sciences Centre, Toronto, Ontario.

Andrew Simor, MD, FRCP, is with the Departments of Medicine and Microbiology, Sunnybrook Health Sciences Centre, Toronto, Ontario.

Michelle Hladunewich, MD, FRCP, is with the Departments of Medicine and Nephrology, Sunnybrook Health Sciences Centre, Toronto, Ontario.

\section{Address correspondence to:}

Dr Sandra A N Walker

Sunnybrook Health Sciences Centre

2075 Bayview Avenue

Department of Pharmacy E-302

Toronto ON M4N 3M5

e-mail: sandra.walker@sunnybrook.ca 